\title{
Feasibility of a three-axis epicardial accelerometer in detecting myocardial ischemia in cardiac surgical patients
}

\author{
Per Steinar Halvorsen, MD, ${ }^{\mathrm{a}}$ Andreas Espinoza, MD, ${ }^{\mathrm{a}}$ Lars Albert Fleischer, MSc, ${ }^{\mathrm{d}}$ Ole Jakob Elle, MSc, PhD, ${ }^{\mathrm{a}}$ Lars Hoff, MSc, \\ $\mathrm{PhD},{ }^{\mathrm{d}}$ Runar Lundblad, MD, PhD, ${ }^{\mathrm{b}}$ Helge Skulstad, MD, PhD, ${ }^{\mathrm{c}}$ Thor Edvardsen, MD, PhD,${ }^{\mathrm{c}, \mathrm{e}}$ Halfdan Ihlen, MD, PhD, ${ }^{\mathrm{a}}$ and \\ Erik Fosse, $\mathrm{MD}, \mathrm{PhD}^{\mathrm{a}, \mathrm{e}}$
}

Objective: We investigated the feasibility of continuous detection of myocardial ischemia during cardiac surgery with a 3 -axis accelerometer.

\begin{abstract}
Methods: Ten patients with significant left anterior descending coronary artery stenosis underwent off-pump coronary artery bypass grafting. A 3-axis accelerometer $(11 \times 14 \times 5 \mathrm{~mm})$ was sutured onto the left anterior descending coronary artery-perfused region of left ventricle. Twenty episodes of ischemia were studied, with 3-minute occlusion of left anterior descending coronary artery at start of surgery and 3-minute occlusion of left internal thoracic artery at end of surgery. Longitudinal, circumferential, and radial accelerations were continuously measured, with epicardial velocities calculated from the signals. During occlusion, accelerometer velocities were compared with anterior left ventricular longitudinal, circumferential, and radial strains obtained by echocardiography. Ischemia was defined by change in strain greater than $30 \%$.
\end{abstract}

Results: Ischemia was observed echocardiographically during 7 of 10 left anterior descending coronary artery occlusions but not during left internal thoracic artery occlusion. During ischemia, there were no significant electrocardiographic or hemodynamic changes, whereas large and significant changes in accelerometer circumferential peak systolic $(P<.01)$ and isovolumic $(P<.01)$ velocities were observed. During 13 occlusions, no ischemia was demonstrated by strain, nor was any change demonstrated by the accelerometer. A strong correlation was found between circumferential strain and accelerometer circumferential peak systolic velocity during occlusion $(r=-0.76, P<.001)$.

Conclusions: The epicardial accelerometer detects myocardial ischemia with great accuracy. This novel technique has potential to improve monitoring of myocardial ischemia during cardiac surgery.

During coronary artery bypass grafting $(\mathrm{CABG})$, blood pressure and electrocardiography (ECG) monitoring lacks accuracy in the detection of regional myocardial ischemia. ${ }^{1}$ Transesophageal echocardiography can detect myocardial ischemia, because ischemia is followed by an immediate decrease in regional myocardial contraction. ${ }^{2-4}$ Quantification of ischemia, however, is usually based on subjective assessment of the heart wall motion. With a 2-dimensional (2D) strain technique, precise description and quantification can be achieved. ${ }^{5-7}$ This method requires complex off-line analysis, however, and thus is unsuitable for continuous monitoring during cardiac surgery.

From The Interventional Centre ${ }^{\mathrm{a}}$ and the Departments of Cardiothoracic Surgery ${ }^{\mathrm{b}}$ and Cardiology, ${ }^{\mathrm{c}}$ Rikshospitalet University Hospital, Oslo, Norway; Vestfold University College, Tønsberg, Norway ${ }^{\mathrm{d}}$; and The Faculty of Medicine, University of Oslo, Oslo, Norway.

P.S.H. was recipient of a clinical research fellowship from the Regional Health Authorities. L.A.F. was recipient of a research fellowship from the Research Council of Norway. A.E. was a recipient of a clinical research fellowship from the Norwegian Council of Cardio-vascular Diseases.

Received for publication May 5, 2008; revisions received Aug 8, 2008; accepted for publication Aug 28, 2008.

Address for reprints: Per Steinar Halvorsen, MD, Rikshospitalet University Hospital, The Interventional Centre, Sognsvannsveien 20, N-0027 Oslo, Norway (E-mail: per.steinar.halvorsen@rikshospitalet.no).

J Thorac Cardiovasc Surg 2008;136:1496-502

$0022-5223 / \$ 34.00$

Copyright $\odot 2008$ by The American Association for Thoracic Surgery doi:10.1016/j.jtcvs.2008.08.043
An accelerometer permits continuous real-time assessments of heart wall motion. ${ }^{8-11}$ Measurements are independent of operator skills, and a 3 -axis accelerometer allows simultaneous assessment of wall motion in the longitudinal, circumferential, and radial directions. This study was designed to investigate whether an epicardial 3-axis accelerometer could detect myocardial ischemia. In patients scheduled for off-pump CABG, occlusions of the left anterior descending coronary artery (LAD) at start of surgery and of the left internal thoracic artery (LITA) at end of surgery were performed to induce myocardial ischemia. The 2D strain obtained by transesophageal echocardiography was used as the reference value for the assessment of ischemia.

\section{METHODS}

\section{Patients and Surgical Procedure}

Patients who had angina pectoris and were scheduled for off-pump CABG were included. All patients had significant LAD stenosis and left ventricular (LV) ejection fraction greater than $35 \%$. Exclusion criteria were previous LAD infarction, anterior wall dyskinesia (judged by preoperative ventriculography or echocardiography), arrhythmias, bundle branch block, and severe peripheral atherosclerosis. The regional ethics committee approved the study, and informed consent was obtained from all patients.

The patients were medicated before the operation with 5 to $10 \mathrm{mg}$ diazepam orally. Anesthesia was induced with 2 to $5 \mu \mathrm{g} / \mathrm{kg}$ fentanyl, thiopentone, 2 to $5 \mathrm{mg} / \mathrm{kg}$, and $0.15 \mathrm{mg} / \mathrm{kg}$ cisatracurium (INN cisatracurium besilate). Repeated doses of fentanyl and sevoflurane $(1.0 \%$ to $2.5 \%)$ were used to maintain anesthesia. Heparin $(1.5 \mathrm{mg} / \mathrm{kg})$ was given to achieve 


$$
\begin{aligned}
& \text { Abbreviations and Acronyms } \\
& \begin{aligned}
2 \mathrm{D} & =2 \text {-dimensional } \\
\mathrm{CABG} & =\text { coronary artery bypass grafting } \\
\mathrm{CI} & =\text { confidence interval } \\
\mathrm{CO} & =\text { cardiac output } \\
\mathrm{dP} / \mathrm{dt} & =\text { positive systolic time derivative of } \\
& \text { femoral arterial blood pressure } \\
\mathrm{ECG}= & \text { electrocardiography } \\
\mathrm{IVR} & =\text { isovolumic relaxation } \\
\mathrm{LAD} & =\text { left anterior descending coronary artery } \\
\text { LITA } & =\text { left internal thoracic artery } \\
\text { LV } & =\text { left ventricle } \\
\text { MAP } & =\text { mean arterial pressure }
\end{aligned}
\end{aligned}
$$

reperfusion. ECG, blood pressures, and pulse-contour CO and LV apical accelerations were continuously recorded. Echocardiographic recordings were obtained at baseline, at the end of LAD occlusion, and after 5 minutes of reperfusion. After bypass grafting was completed, the LITA was manually occluded for 3 minutes. Before LITA occlusion, activated clotting time was ensured to be above 250s. The same measurements described here were performed during LITA occlusion and reperfusion. Transit-time flow measurements with a 3-mm probe (Medistim KirOp AS, Oslo, Norway) of the LITA graft were obtained before, during, and after LITA occlusion. No manipulation of heart or body positions occurred during the occlusions of the LAD and LITA. In addition, vasoactive medications and fluid infusions were kept unchanged.

The 2D-strain was used as the reference method for the detection of ischemia. Ischemia was defined as a relative change in systolic strain greater than $30 \%$ in either direction. ${ }^{13}$ This cutoff was based on the fact that measurements of physiologic variables often lack precision, with errors of $10 \%$ to $20 \%$ not uncommon. ${ }^{14,15}$ Similarly, a change in either direction of the accelerometer recordings in peak systolic or isovolumic relaxation (IVR) velocity greater than $30 \%$ was defined as ischemia.

an activated clotting time longer than 250 seconds. After sternotomy and pericardial opening, a prototype 3-axis accelerometer was sutured on the LV anterior apical region (Figure 1). A snare was placed around LAD distally to the first diagonal branch. The chest and the pericardium were left open, with the patients in the supine position.

\section{Pressures and Cardiac Output Measurements}

A radial artery catheter and a central venous-internal jugular catheter were placed. A 5F arterial thermodilution catheter (PV 2025L20; Pulsion Medical Systems AG, Munich, Germany) was inserted in the right femoral artery and connected to a pressure transducer (PV8115; Pulsion Medical). The signals were computed with a PiCCO monitor (version 5.1; Pulsion Medical). A PiCCO inline injectate temperature sensor was fitted in the central venous line for transpulmonary thermodilution cardiac output (CO) measurements. Three boluses of $10 \mathrm{~mL}$ ice-cold $5 \%$ glucose solution were injected into the central line, and the mean $\mathrm{CO}$ value was used to calibrate the pulse-contour $\mathrm{CO}$. All catheters were zeroed before the interventions. The software program ICUPilot (CMA Microdialysis AB, Solna, Sweden) was used to collect the pressure variable data.

\section{Echocardiography}

A Vivid 7 scanner (GE Vingmed Ultrasound AS, Horten, Norway) with a transesophageal transducer was used. Two-dimensional gray-scale recordings were obtained in 2- and 4-chamber views and in apical short-axis view. Longitudinal, circumferential, and radial LV functions were assessed with the $2 \mathrm{D}$ strain technique. ${ }^{5-7}$ This method, which calculates myocardial deformation from ultrasound speckles in the gray-scale images, is semiautomatic and angle independent. EchoPAC (GE Vingmed Ultrasound) was used for off-line analysis.

\section{Accelerometer}

We used a prototype 3 -axis capacitive accelerometer (outer dimensions $11.0 \times 14.5 \times 5.2 \mathrm{~mm}),{ }^{12}$ with range $\pm 2 \mathrm{G}$ and cross-sensitivity between axes of $2 \%$. The acceleration and ECG signals were recorded synchronously at a sampling rate of 250 to $500 \mathrm{~Hz}$ with an NI USB 6009 AD converter (National Instruments Corporation, Franklin Park, Ill) and LabVIEW software (National Instruments). All signals were stored on a personal computer and analyzed off-line with Matlab (The MathWorks, Inc, Natick, Mass).

\section{Experimental Protocol}

After opening of the pericardium before CABG, baseline recordings were obtained with stable hemodynamics. Before grafting on the LAD, a 3-minute occlusion of LAD was performed, followed by 5 minutes of

\section{Calculations}

Measurements of the ECG ST-segment were performed $80 \mathrm{~ms}$ from the ECG J-point. Mean arterial blood pressure (MAP), pulse-contour CO, and the positive systolic time derivative of the femoral arterial blood pressure $(\mathrm{dP} / \mathrm{dt})$ were assessed from the PiCCO catheter recordings. Systole was defined from the start of R on ECG to aortic valve closure, defined by a sharp spike in the acceleration signal. ${ }^{16}$ Diastole was defined from aortic valve closure to the start of R on ECG. The IVR phase was defined from aortic valve closure to mitral valve opening, as assessed by the acceleration signal. ${ }^{16}$

Peak systolic strains in the longitudinal, circumferential, and radial directions were calculated as percentages of LV end-diastolic dimensions. The mean of three consecutive heart cycles was used for statistical calculations. Frame rate was $69 \pm 12$ frames/s.

The acceleration signals were integrated to obtain epicardial velocities. ${ }^{17}$ Peak early systolic velocity and velocity in the IVR phase were measured. ${ }^{18}$ The accelerometer $\mathrm{x}$-axis measured longitudinal velocity, the $\mathrm{y}$-axis measured circumferential velocity, and the z-axis measure radial velocity (Figure 1). The mean of three consecutive heart cycles was used for statistical analysis. To assess interobserver variability, all baselines and occlusions were analyzed by another investigator who was blinded to the results from the reference method.

\section{Statistical Analysis}

The number of patients included was based on a power analysis. During ischemia, a clinical significant change in accelerometer peak velocity was set to $5.0 \mathrm{~cm} / \mathrm{s}(\mathrm{SD} 5.0 \mathrm{~cm} / \mathrm{s})$. With $\alpha=.05$, this yielded a power of 0.80 with 8 patients included. Parametric statistical methods were used, and data are presented as mean $\pm \mathrm{SD}$ (SD of sample distribution). For repeated measurements, paired-sample $t$ tests were applied. To adjust for multiple comparisons, Bonferroni corrections of $P$ values were performed. For the correlation analysis, the Pearson correlation coefficient was calculated. Sensitivity and specificity were computed from standard table analysis, and the $95 \%$ confidence intervals (CIs) were constructed with the f-distribution. To assess interobserver variability, the Bland-Altman method was applied. ${ }^{19}$ All statistical analyses were performed with SPSS statistical software (version 13.0, SPSS Inc; Chicago, Ill).

\section{RESULTS}

\section{Patients}

Ten patients ( 8 men and 2 women) were enrolled, with a mean age of $61 \pm 7$ years, a mean weight of $91 \pm 16$ 


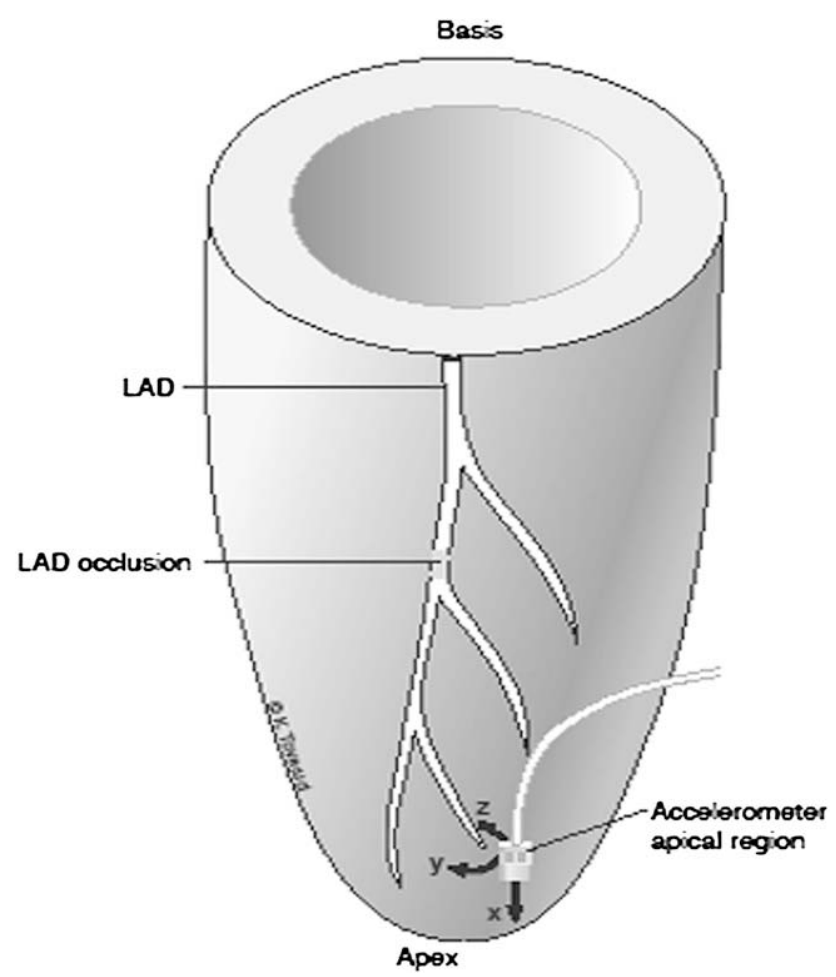

FIGURE 1. Schematic illustration of anterior view of left ventricle showing 3-axis accelerometer placed in left anterior descending coronary artery $(L A D)$ perfusion area. Epicardial systolic wall motions are indicated with arrows; for 3-axis accelerometer, $x$ arrow specifies longitudinal epicardial wall motion, y arrow specifies circumferential wall motion, and $z$ arrow specifies radial wall motion. Level of occlusion of left anterior descending coronary artery is also indicated.

$\mathrm{kg}$, a mean height of $176 \pm 10 \mathrm{~cm}$, a mean New York Heart Association functional class of $2.5 \pm 0.5$, a mean LV ejection fraction of $0.65 \pm 10$, and a mean LV end-diastolic pressure of $12 \pm 4 \mathrm{~mm} \mathrm{Hg}$. Five patients had previous myocardial infarction, with 2 right and 3 circumflex coronary artery infarctions. Five patients had hypertension, 2 had diabetes, and 8 received $\beta$-blockers. All patients had significant stenosis of the LAD and the circumflex coronary artery, and 7 had additional stenosis of the right coronary artery. In all cases, the LAD was grafted with the LITA, except for 1 patient who had a $100 \%$ distal LAD occlusion. In that case, and for all other coronary arteries, saphenous veins were used for grafting. The number of distal coronary anastomoses was $2.3 \pm 0.5$. There were no conversion to onpump technique, no deaths, and no myocardial or cerebral infarctions. Fluid administered was $4710 \pm 1943 \mathrm{~mL}$, and blood loss was estimated to $483 \pm 494 \mathrm{~mL}$. No erythrocyte concentrate was given, and the hemoglobin concentrations were $13.3 \pm 1.5 \mathrm{~g} / \mathrm{dL}$ at the start and $11.7 \pm 1.4 \mathrm{~g} / \mathrm{dL}$ at end of surgery $(P<.01)$. All patients were externally warmed, and rectal temperature was $36.4^{\circ} \mathrm{C} \pm 0.3^{\circ} \mathrm{C}$ at start and $36.2^{\circ} \mathrm{C} \pm 0.3^{\circ} \mathrm{C}$ at end of surgery (difference not significant).

\section{LAD and LITA occlusions}

Twenty occlusions were performed (10 LAD occlusions and 10 LITA occlusions). Ischemia, defined as changes in strain greater than $30 \%$, developed in 7 of 10 LAD occlusions. No ischemia was observed during three LAD occlusions. One of these patients had a $100 \%$ distal LAD occlusion with no retrograde blood flow, and another had extensive collaterals to the $\mathrm{LV}$ apical region from the right coronary artery. LITA occlusion was not associated with myocardial ischemia in any patient.

The ST segment of the standard ECG lead II did not change significantly from baseline in the 7 patients with ischemia according to strain during LAD occlusion. ST-segment depression greater than $0.1 \mathrm{mV}$ was not found in any patient. In addition, no significant changes in pulse-contour $\mathrm{CO}$, mean arterial pressure, heart rate central venous pressure, and $\mathrm{dP} / \mathrm{dt}$ were observed (Table 1 ). In contrast, marked changes in longitudinal, circumferential, and radial systolic strains were seen during ischemia $(P<.01$; Table 1$)$. These values returned to baseline after 5 minutes of reperfusion. Figure 2 shows representative circumferential velocity curves generated from the accelerometer at baseline and during ischemia and reperfusion.

During ischemia $(\mathrm{n}=7)$, for the accelerometer peak systolic velocities, a significant decrease in the circumferential directions was seen $(12.9 \pm 5.9$ to $6.0 \pm 2.7 \mathrm{~cm} / \mathrm{s}, P<.01$; Table 1). No such changes were observed in the longitudinal and radial velocities. After reperfusion of the LAD, the epicardial peak systolic velocities equaled baseline values.

Increases in accelerometer velocities in the IVR phase were observed in all directions during ischemia. A significant change, however, was only found in the circumferential direction $(-6.5 \pm 4.0$ to $2.0 \pm 7.3, P<.001$; Table 1$)$.

During 13 occlusions without ischemia according to strain data, no significant changes were observed in the ECG ST-segment, pulse-contour CO, MAP, heart rate, central venous pressure, $\mathrm{dP} / \mathrm{dt}$, or accelerometer velocities (Table 1).

Individual changes in circumferential strain and accelerometer circumferential peak systolic velocity for all LAD occlusions can be seen in Figure 3. A strong negative correlation was observed between circumferential systolic strain and accelerometer circumferential peak systolic velocity during LAD and LITA occlusions (Figure 4). In the 7 occlusions where ischemia was demonstrated by strain measurements, the accelerometer also exhibited ischemia. Ischemia was not found on accelerometer recordings in the 13 occlusions where strain did not show ischemia. The accelerometer therefore demonstrated a sensitivity of $100 \%(95 \%$ CI $56 \%-100 \%)$, a specificity of $100 \%(95 \%$ CI $72 \%-100 \%)$, a positive predictive value 
TABLE 1. Hemodynamics, accelerometer velocities, and echocardiographic 2-dimensional strain during left anterior descending coronary arterial and left internal thoracic arterial occlusions $(\mathbf{n}=\mathbf{2 0})$

\begin{tabular}{|c|c|c|c|}
\hline & Baseline & Occlusion & After occlusion (5 min) \\
\hline \multicolumn{4}{|l|}{ Ischemia $(n=7)$} \\
\hline Pulse-contour cardiac output (L/min) & $5.4 \pm 1.0$ & $5.2 \pm 1.2$ & $5.2 \pm 1.0$ \\
\hline Mean arterial pressure $(\mathrm{mm} \mathrm{Hg})$ & $80 \pm 12$ & $78 \pm 11$ & $79 \pm 11$ \\
\hline Heart rate (beats/min) & $73 \pm 8$ & $72 \pm 8$ & $71 \pm 7$ \\
\hline Central venous pressure $(\mathrm{mm} \mathrm{Hg})$ & $8 \pm 4$ & $8 \pm 3$ & $8 \pm 3$ \\
\hline $\mathrm{dP} / \mathrm{dt}(\mathrm{mm} \mathrm{Hg} / \mathrm{s})$ & $771 \pm 233$ & $698 \pm 224$ & $763 \pm 253$ \\
\hline \multicolumn{4}{|l|}{ Echocardiographic systolic strain (\%) } \\
\hline Longitudinal & $-26.2 \% \pm 9.1 \%$ & $-2.5 \% \pm 12.8 \% \dagger$ & $-28.3 \% \pm 7.6 \%$ \\
\hline Circumferential & $-24.4 \% \pm 6.0 \%$ & $4.1 \% \pm 8.9 \% \dagger$ & $-22.0 \% \pm 4.0 \%$ \\
\hline Radial & $38.3 \% \pm 5.9 \%$ & $5.5 \% \pm 15.1 \% \dagger$ & $34.2 \% \pm 9.6 \%$ \\
\hline \multicolumn{4}{|c|}{ Accelerometer peak systolic velocity $(\mathrm{cm} / \mathrm{s})$} \\
\hline Longitudinal & $8.3 \pm 6.6$ & $5.3 \pm 3.0$ & $6.9 \pm 5.3$ \\
\hline Circumferential & $12.9 \pm 5.9$ & $6.0 \pm 2.7^{*}$ & $12.5 \pm 4.9$ \\
\hline Radial & $6.5 \pm 5.1$ & $3.7 \pm 3.2$ & $6.2 \pm 4.2$ \\
\hline \multicolumn{4}{|l|}{ Accelerometer IVR velocity $(\mathrm{cm} / \mathrm{s})$} \\
\hline Longitudinal & $-3.2 \pm 2.2$ & $-1.5 \pm 5.4$ & $-3.7 \pm 2.8$ \\
\hline Circumferential & $-6.5 \pm 4.0$ & $2.0 \pm 7.3^{*}$ & $-5.0 \pm 4.4$ \\
\hline Radial & $-1.3 \pm 2.4$ & $-0.1 \pm 2.1$ & $-1.0 \pm 1.9$ \\
\hline \multicolumn{4}{|l|}{ No ischemia $(n=13)$} \\
\hline Pulse-contour cardiac output (L/min) & $5.5 \pm 1.2$ & $5.5 \pm 1.3$ & $5.5 \pm 1.4$ \\
\hline Mean arterial pressure $(\mathrm{mm} \mathrm{Hg})$ & $74 \pm 9$ & $71 \pm 9$ & $69 \pm 10$ \\
\hline Heart rate (beats/min) & $69 \pm 11$ & $70 \pm 11$ & $71 \pm 11$ \\
\hline Central venous pressure $(\mathrm{mm} \mathrm{Hg})$ & $10 \pm 4$ & $9 \pm 4$ & $9 \pm 4$ \\
\hline $\mathrm{dP} / \mathrm{dt}(\mathrm{mm} \mathrm{Hg} / \mathrm{s})$ & $575 \pm 150$ & $585 \pm 147$ & $584 \pm 150$ \\
\hline \multicolumn{4}{|l|}{ Echocardiographic systolic strain (\%) } \\
\hline Longitudinal & $-25.2 \% \pm 4.4 \%$ & $-24.8 \% \pm 4.2 \%$ & $-22.7 \% \pm 3.7 \%$ \\
\hline Circumferential & $-23.6 \% \pm 3.7 \%$ & $-25.7 \% \pm 6.3 \%$ & $-22.7 \% \pm 4.9 \%$ \\
\hline Radial & $39.1 \% \pm 10.9 \%$ & $37.9 \% \pm 10.8 \%$ & $35.8 \% \pm 12.8 \%$ \\
\hline \multicolumn{4}{|c|}{ Accelerometer peak systolic velocity $(\mathrm{cm} / \mathrm{s})$} \\
\hline Longitudinal & $9.0 \pm 4.6$ & $10.3 \pm 4.9$ & $11.0 \pm 4.3$ \\
\hline Circumferential & $12.4 \pm 4.1$ & $13.2 \pm 3.8$ & $13.2 \pm 4.0$ \\
\hline Radial & $5.5 \pm 3.4$ & $5.9 \pm 3.1$ & $6.1 \pm 3.8$ \\
\hline \multicolumn{4}{|l|}{ Accelerometer IVR velocity $(\mathrm{cm} / \mathrm{s})$} \\
\hline Longitudinal & $-2.3 \pm 2.6$ & $-3.1 \pm 2.8$ & $-3.8 \pm 2.4$ \\
\hline Circumferential & $-1.7 \pm 4.8$ & $-2.1 \pm 4.4$ & $-2.3 \pm 5.4$ \\
\hline Radial & $0.2 \pm 2.3$ & $-0.1 \pm 2.3$ & $0.0 \pm 2.5$ \\
\hline
\end{tabular}

Values are mean $\pm \mathrm{SD} . d P / d t$, Positive systolic time derivative of femoral arterial blood pressure; $I V R$, isovolumic relaxation phase. $* P<.01$ from baseline (after Bonferroni correction). $\dagger P<.05$ from baseline (after Bonferroni correction).

of $100 \%(95 \%$ CI $56 \%-100 \%)$, and a negative predictive value of $100 \%(95 \%$ CI $72 \%-100 \%)$ in detecting ischemia.

\section{Interobserver Variation}

The interobserver variation of the accelerometer circumferential peak systolic velocity was low, with a correlation coefficient of $0.97(P<.001)$ and a mean difference between the two analyses of $0.3 \pm 2.6 \mathrm{~cm} / \mathrm{s}$.

\section{DISCUSSION}

In this feasibility study, a 3-axis epicardial accelerometer detected ischemic events during cardiac surgery. The accelerometer circumferential velocities, in contrast to ST-seg- ment analysis and hemodynamic measurements, changed significantly during ischemia. Importantly, the accelerometer demonstrated a similar ability to detect myocardial ischemia as 2D strain measured by echocardiography. These results indicate that this novel technique may be used in cardiac surgery for continuous real-time monitoring of myocardial ischemia.

The main finding in this study was that the accelerometer showed highly significant circumferential velocities changes during myocardial ischemia, whereas no changes could be seen in ECG and hemodynamics. The accelerometer demonstrated high sensitivity and specificity in the detection of myocardial ischemia. These findings, together with the strong negative correlation observed between 2D strain 


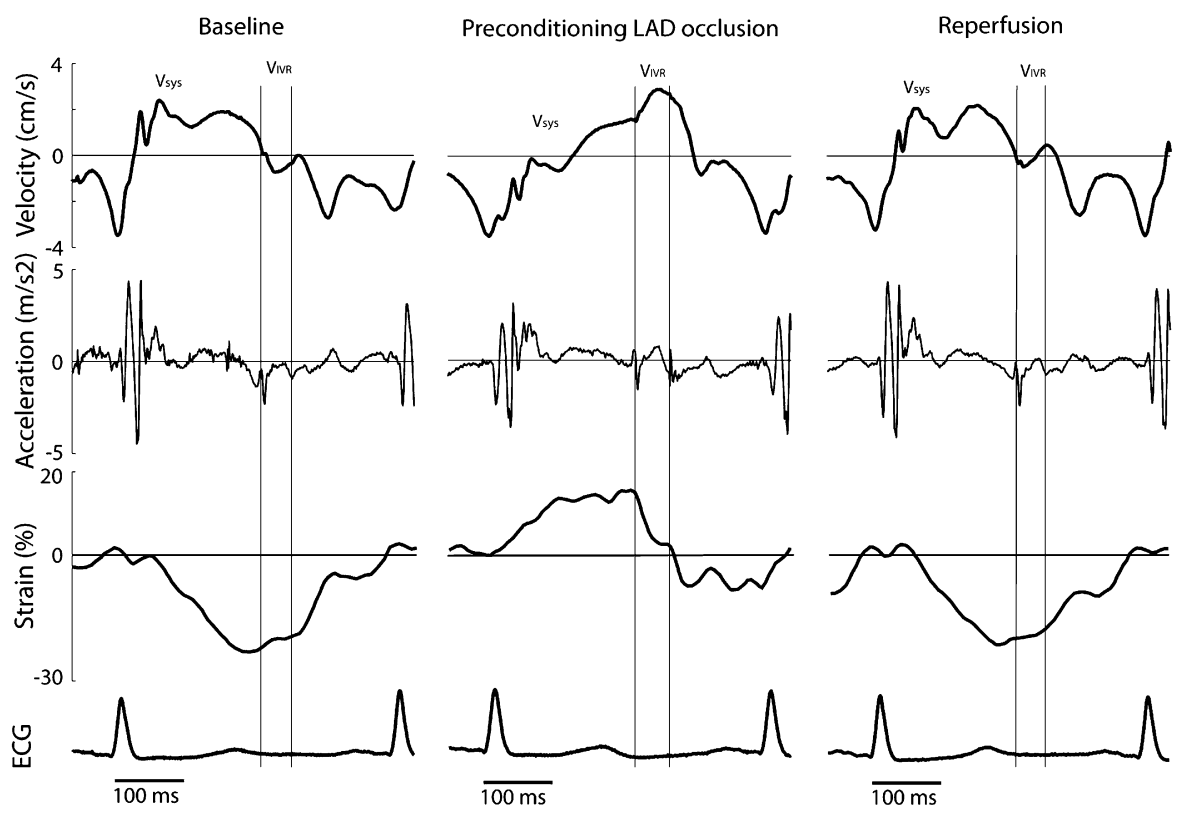

FIGURE 2. Representative left ventricular curves from single patient of accelerometer circumferential velocity and acceleration, echocardiographic 2-dimensional strain, and electrocardiography $(E C G)$ at baseline, during ischemia, and after reperfusion. Peak systolic velocity $\left(V_{\text {sys }}\right)$ and velocity in isovolumic relaxation phase $\left(V_{i v r}\right)$ are indicated. Isovolumic relaxation phase is indicated by lines and defined within distinct spikes in acceleration signal caused by aortic valve closure and mitral valve opening. During ischemia, greatest changes can be seen in accelerometer velocity and strain curves, whereas no changes in electrocardiography can be seen. $L A D$, Left anterior descending coronary artery.

and circumferential peak systolic velocity, prove that accelerometer recordings may be applied successfully in the monitoring of myocardial ischemia.

Echocardiographic 2D strain was used as reference method, because this technique has the confirmed ability to detect and quantify myocardial ischemia. ${ }^{5-7}$ In this study, the LAD and LITA were occluded during stable hemodynamic periods, because a large decrease in LV function most likely would be caused by myocardial ischemia. Measurements of physiologic variables may vary $10 \%$ to $20 \%$ in either direction during stable hemodynamic conditions, ${ }^{14,15}$ and a relative decrease in myocardial function greater than $30 \%$ was therefore made a cutoff for the definition of ischemia.

In contrast to echocardiographic methods, accelerometer recordings are operator independent and have the potential for continuous real-time monitoring of myocardial ischemia. Velocities were calculated from the acceleration signals for two reasons. First, mitral valve closure may generate large systolic accelerations that do not necessarily reflect myocardial contraction. ${ }^{11,20,21}$ Second, velocity is an established and frequently used parameter for measuring myocardial ischemia. ${ }^{18,22}$ There is, however, a distinction between echocardiographic tissue velocity imaging and the accelerometer in assessing myocardial velocity. The ultrasonographic technique measures the velocity in one direction within the wall, whereas with the accelerometer, epicardial velocities are assessed simultaneously in three directions. Even so, the epi- cardial velocity traces appeared similar to traces generated by the ultrasonographic technique. ${ }^{18,22}$ During ischemia, a typical ischemic velocity pattern was observed, with a decrease in early peak systolic velocity and an increase in IVR velocity. Opening and closure of the mitral and aortic valves are reflected as distinct spikes in the acceleration signal. By recording ECG and acceleration simultaneously, the systolic and diastolic phases of the heart cycle were made easier to identify than with the ultrasonic technique.

Significant changes were observed only in the circumferential direction and not in the other axes. This may be due to the effects of pericardiotomy and the resulting loss of pericardial constraint. Pericardiotomy causes abnormal longitudinal apex motion, ${ }^{23,24}$ whereas LV rotation is unaffected. ${ }^{7}$ Radial myocardial contraction is caused by shortening of longitudinally and circumferentially oriented fibers, ${ }^{25-27}$ and therefore abnormal longitudinal contraction may affect radial motion. In the LV apical region, however, myocardial contraction is dominated by circumferentially orientated fibers, and it is therefore likely that the largest effects may be seen in the epicardial circumferential velocities during ischemia. The capability of the accelerometer to detect minor subepicardial or endocardial ischemia is unknown. The subepicardial and endocardial fibers are oriented longitudinally, but as myocardial deformation during ejection demonstrates extensive transmural tethering ${ }^{28}$ an accelerometer placed on the epicardial surface may possibly detect subendocardial ischemia. Further studies are needed to draw firm conclusions. 

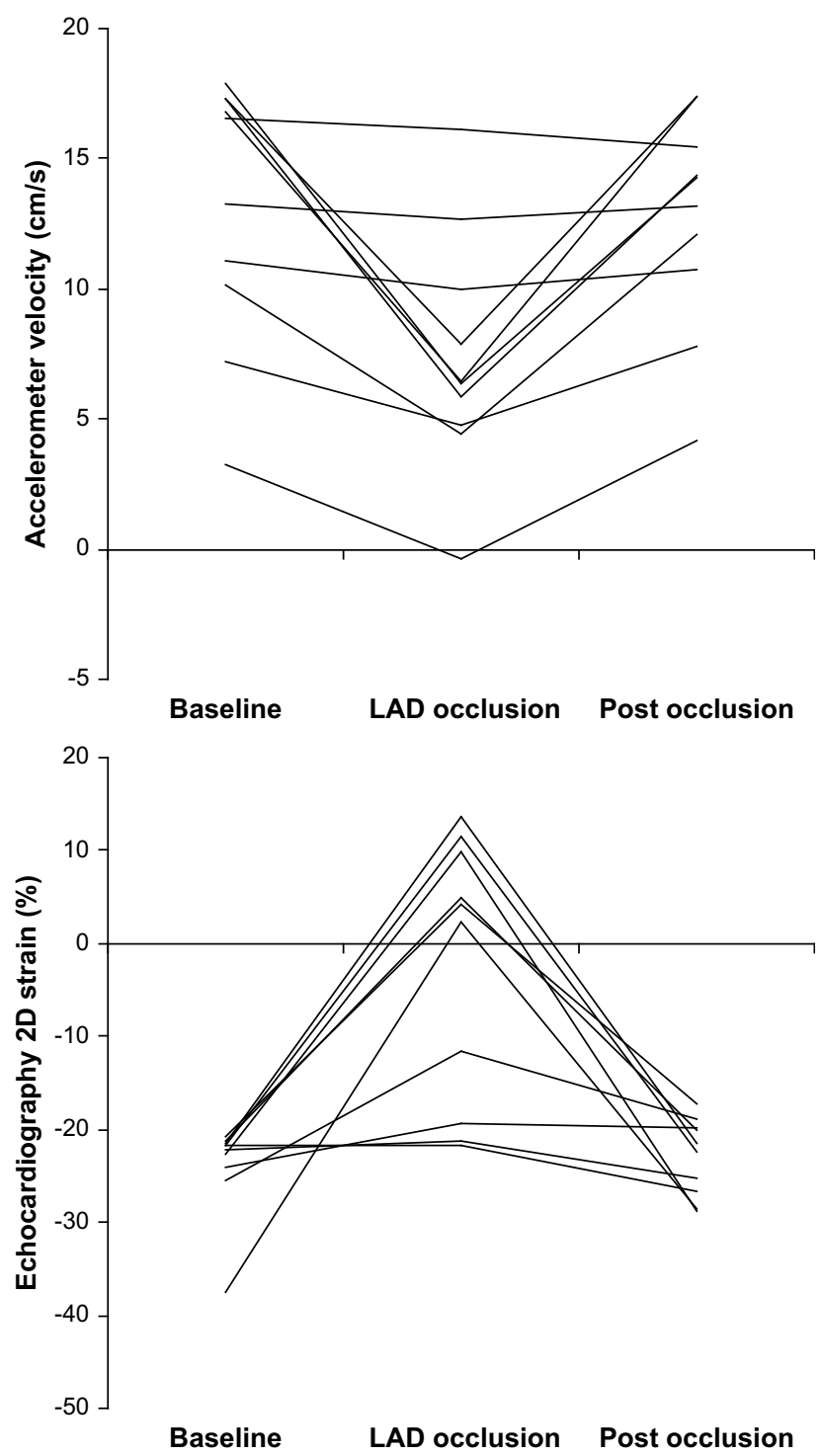

FIGURE 3. Echocardiographic circumferential 2-dimensional $(2 D)$ strains and accelerometer circumferential peak systolic velocities at baseline, left anterior descending coronary arterial $(L A D)$ occlusion, and reperfusion for all patients.

Intraoperative ischemia is a predictor of postoperative myocardial infarction. ${ }^{1,29}$ Nevertheless, postoperative infarction may frequently occur without previously detected intraoperative ischemia. ${ }^{1}$ This emphasizes the need for sustained, continuous, and sensitive detection of ischemia even in the postoperative period. Echocardiography is an excellent tool to assess intraoperative ischemia, but the method is cumbersome and not routinely applied for continuous monitoring after surgery. For this period, the accelerometer may offer an important advantage relative to commonly used monitoring modalities. The development of an algorithm for automatic analysis of the accelerometer signals and further miniaturization of the device will be necessary for clinical

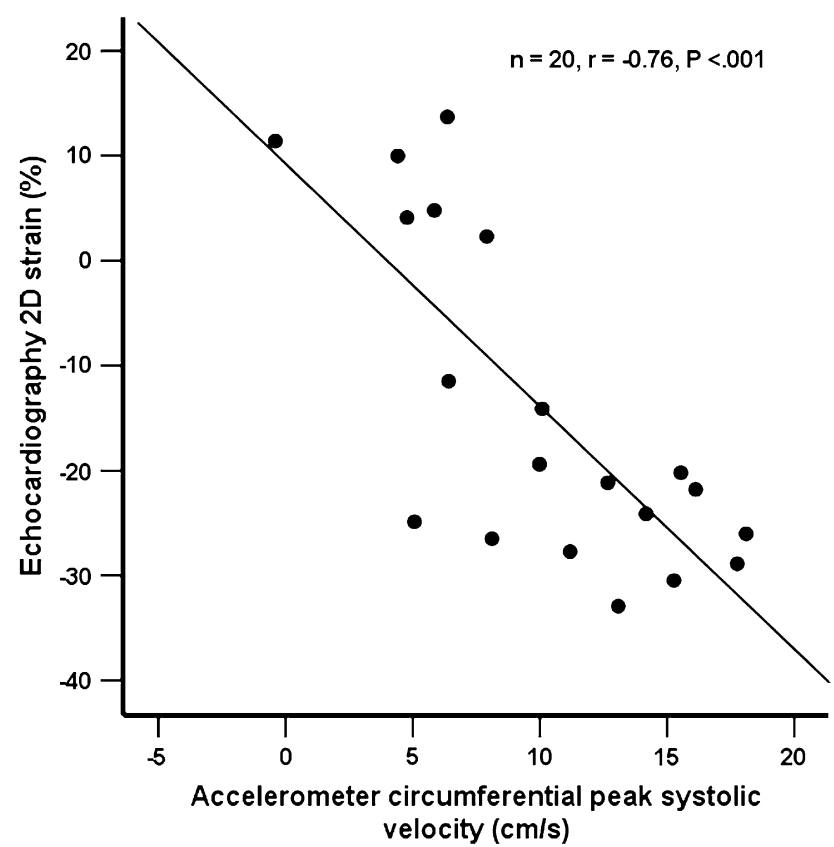

FIGURE 4. Correlation between echocardiographic circumferential 2 dimensional $(2 D)$ strains and accelerometer circumferential peak systolic velocities for left anterior descending coronary arterial and left internal thoracic arterial occlusions.

implementation. The accelerometer could be incorporated into temporary pacemaker leads, minimizing invasiveness while enabling continued detection of ischemia.

Collateral flow from other coronary arteries may explain the lack of ischemic changes during LAD occlusion in 3 patients. In the experiments with occlusion of the LITA graft, collateral flow and continued flow through the native LAD may explain the lack of ischemic changes. These observations indicate that the monitoring of velocities from an accelerometer, although able to detect ischemia, may not always be able to detect malfunction of grafts. This drawback, however is also seen with ECG and echocardiography. Accelerometers not only may be used to monitor ischemia in CABG surgery but may possibly be applied to all cardiac surgery procedures where ischemia can occur.

\section{Limitations}

Measurements were performed in stable periods and not during bypass grafting, where surgical manipulation to a great extent affect $L V$ performance.

Assessment of ischemia by transesophageal echocardiography may be performed in multiple heart regions. This study cannot be used to draw conclusions as to whether more than one accelerometer would be required to monitor the different heart regions. Apex motion has been shown to be affected by ischemia from all coronary arteries. ${ }^{10}$ An accelerometer attached to the LV apical anterior region might therefore be sufficient for detecting ischemia in various heart regions. 
Repeated LAD occlusions may induced myocardial preconditioning, thereby decreasing the accelerometer changes caused by LITA occlusion. We consider this effect to be minor. The accelerometer may have limited utility in patients whose myocardium is "stunned" or "hibernating" at the start of surgery, because such patients have reduced baseline contractility. ${ }^{30}$

\section{CONCLUSIONS}

To our knowledge, this study represents the first demonstration of continuous detection of myocardial ischemia by a 3-axis accelerometer in cardiac surgical patients. Circumferential velocity measured by the accelerometer was superior to ECG and hemodynamic measurements in the continuous detection of ischemia and correlated strongly with echocardiographic 2D strain. This new technique has the potential for improving monitoring during and after cardiac surgery.

We thank statistician Milada Cvancarova Småstuen for valuable statistical assistance.

\section{References}

1. Comunale ME, Body SC, Ley C, Koch C, Roach G, Mathew JP, et al. The concordance of intraoperative left ventricular wall-motion abnormalities and electrocardiographic S-T segment changes: association with outcome after coronary revascularization. Multicenter Study of Perioperative Ischemia (McSPI) Research Group. Anesthesiology. 1998;88:945-54.

2. Derumeaux G, Ovize M, Loufoua J, André-Fouet X, Minaire Y, Cribier A, et al. Doppler tissue imaging quantitates regional wall motion during myocardial ischemia and reperfusion. Circulation. 1998;97:1970-7.

3. Edvardsen T, Aakhus S, Endresen K, Bjomerheim R, Smiseth OA, Ihlen H. Acute regional myocardial ischemia identified by 2 -dimensional multiregion tissue Doppler imaging technique. J Am Soc Echocardiogr. 2000;13:986-94.

4. Kotoh K, Watanabe G, Ueyama K, Uozaki M, Suzuki M, Misaki T, et al. On-line assessment of regional ventricular wall motion by transesophageal echocardiography with color kinesis during minimally invasive coronary artery bypass grafting. J Thorac Cardiovasc Surg. 1999;117:912-7.

5. Amundsen B, Helle-Valle T, Edvardsen T, Torp H, Crosby J, Lyseggen E, et al. Noninvasive myocardial strain measurement by speckle tracking echocardiography: validation against sonomicrometry and tagged magnetic resonance imaging. J Am Coll Cardiol. 2006;47:789-93.

6. Gjesdal O, Hopp E, Vartdal T, Lunde K, Helle-Valle T, Aakhus S, et al. Global longitudinal strain measured by two-dimensional speckle tracking echocardiography is closely related to myocardial infarct size in chronic ischaemic heart disease. Clin Sci (Lond). 2007;113:287-96.

7. Helle-Valle T, Crosby J, Edvardsen T, Lyseggen E, Amundsen B, Smith HJ, et al. New noninvasive method for assessment of left ventricular rotation: speckle tracking echocardiography. Circulation. 2005;112:3149-56.

8. Elle OJ, Halvorsen S, Gulbrandsen MG, Aurdal L, Bakken A, Samset E, et al. Early recognition of regional cardiac ischemia using a 3-axis accelerometer sensor. Physiol Meas. 2005;26:429-40.

9. Pauliks LB, Vogel M, Madler CF, Williams RI, Payne N, Redington AN, et al. Regional response of myocardial acceleration during isovolumic contraction during dobutamine stress echocardiography: a color tissue Doppler study and comparison with angiocardiographic findings. Echocardiography. 2005;22:797-808.

10. Theres HP, Kaiser DR, Nelson SD, Glos M, Leuthold T, Baumann G, et al. Detection of acute myocardial ischemia during percutaneous transluminal coronary angioplasty by endocardial acceleration. Pacing Clin Electrophysiol. 2004;27: 621-5.

11. Wood JC, Festen MP, Lim MJ, Buda AJ, Barry DT. Regional effects of myocardial ischemia on epicardially recorded canine first heart sounds. J Appl Physiol. 1994;76:291-302.

12. Imenes K, Aasmundtveit K, Husa EM, Høgetveit JO, Halvorsen S, Elle OJ, et al. Assembly and packaging of a three-axis micro accelerometer used for detection of heart infarction. Biomed Microdevices. 2007;9:951-7.

13. Skulstad H, Urheim S, Edvardsen T, Andersen K, Lyseggen E, Vartdal T, et al. Grading of myocardial dysfunction by tissue Doppler echocardiography: a comparison between velocity, displacement, and strain imaging in acute ischemia. J Am Coll Cardiol. 2006;47:1672-82.

14. Salandin V, Zussa C, Risica G, Michielon P, Paccagnella A, Cipolotti G, et al. Comparison of cardiac output estimation by thoracic electrical bioimpedance, thermodilution, and Fick methods. Crit Care Med. 1988;16:1157-8.

15. Stetz CW, Miller RG, Kelly GE, Raffin TA. Reliability of the thermodilution method in the determination of cardiac output in clinical practice. Am Rev Respir Dis. 1982;126:1001-4.

16. Aase SA, Stoylen A, Ingul CB, Frigstad S, Torp H. Automatic timing of aortic valve closure in apical tissue Doppler images. Ultrasound Med Biol. 2006;32: 19-27.

17. Hoff L, Elle OJ, Grimnes MJ, Halvorsen S, Alker HJ, Fosse E. Measurements of heart motion using accelerometers. Conf Proc IEEE Eng Med Biol Soc. 2004;3: 2049-51.

18. Edvardsen T, Urheim S, Skulstad H, Steine K, Ihlen H, Smiseth OA. Quantification of left ventricular systolic function by tissue Doppler echocardiography: added value of measuring pre- and postejection velocities in ischemic myocardium. Circulation. 2002;105:2071-7.

19. Bland JM, Altman DG. Statistical methods for assessing agreement between two methods of clinical measurement. Lancet. 1986;1:307-10.

20. Lyseggen E, Rabben SI, Skulstad H, Urheim S, Risoe C, Smiseth OA. Myocardial acceleration during isovolumic contraction: relationship to contractility. Circulation. 2005;111:1362-9.

21. Rickards AF, Bombardini T, Corbucci G, Plicchi G. An implantable intracardiac accelerometer for monitoring myocardial contractility. The Multicenter PEA Study Group. Pacing Clin Electrophysiol. 1996;19:2066-71.

22. Takayama M, Norris RM, Brown MA, Armiger LC, Rivers JT, White HD. Postsystolic shortening of acutely ischemic canine myocardium predicts early and late recovery of function after coronary artery reperfusion. Circulation. 1988;78: 994-1007.

23. Gibbons Kroeker CA, Adeeb S, Tyberg JV, Shrive NG. A 2D FE model of the heart demonstrates the role of the pericardium in ventricular deformation. Am J Physiol Heart Circ Physiol. 2006;291:H2229-36.

24. Skulstad H, Andersen K, Edvardsen T, Rein KA, Tønnessen TI, Hol PK, et al. Detection of ischemia and new insight into left ventricular physiology by strain Doppler and tissue velocity imaging: assessment during coronary bypass operation of the beating heart. J Am Soc Echocardiogr. 2004;17:1225-33.

25. Rademakers FE, Rogers WJ, Guier WH, Hutchins GM, Siu CO, Weisfeldt ML, et al. Relation of regional cross-fiber shortening to wall thickening in the intact heart. Three-dimensional strain analysis by NMR tagging. Circulation. 1994; 89:1174-82.

26. Rankin JS, McHale PA, Arentzen CE, Ling D, Greenfield JC Jr, Anderson RW. The three-dimensional dynamic geometry of the left ventricle in the conscious dog. Circ Res. 1976;39:304-13.

27. Sengupta PP, Khandheria BK, Korinek J, Wang J, Belohlavek M. Biphasic tissue Doppler waveforms during isovolumic phases are associated with asynchronous deformation of subendocardial and subepicardial layers. J Appl Physiol. 2005; 99:1104-11.

28. McCulloch AD, Sung D, Wilson JM, Pavelec RS, Omens JH. Flow-function relations during graded coronary occlusions in the dog: effects of transmural location and segment orientation. Cardiovasc Res. 1998;37:636-45.

29. Landesberg G, Mosseri M, Zahger D, Wolf Y, Perouansky M, Anner H, et al. Myocardial infarction after vascular surgery: the role of prolonged stress-induced, ST depression-type ischemia. J Am Coll Cardiol. 2001;37:1839-45.

30. Kloner RA, Jennings RB. Consequences of brief ischemia: stunning, preconditioning, and their clinical implications: part 1. Circulation. 2001;104:2981-9. 